Healthy meals, better learners? Debating the focus of school food policy in England.

Lexi Earl ${ }^{\mathrm{a}}$ and Gurpinder Singh Lalli ${ }^{\mathrm{b}}$

${ }^{a}$ Future Food Beacon, University, of Nottingham, Nottingham, East Midlands

lexi.earl2@notingham.ac.uk

${ }^{b}$ Institute of Education, University of Wolverhampton, Walsall, West Midlands, glalli@wlv.ac.uk 


\section{Healthy meals, better learners? Debating the focus of school food policy in England.}

Policy makers in the UK are trying to improve school meals, by focusing on eating well. This article explores the way policies are framed by academic performance and health as a reason for providing school lunches. Using Nussbaum's capability approach we argue that the purpose of schooling should be to provide young people with the ability to lead a life of choice. We argue that school meals are an important social good, which allow young people to develop critical skills around food which they can then use throughout their lives. We draw on evidence from two ethnographic research projects on food in schools, conducted in England. We question whether the collocation between healthy eating and learning should be the focus of school food reform and contemplate the role of society and government to provide children with healthy meals, irrespective of learning outcomes. School meals are more than good exam results.

Keywords: school meals; policy, social learning; healthy citizen

School Food, Meals and Policy in England

School meals policy tends to centre on providing nutritionally balanced school lunches, with possibilities for food education if possible. Less is written about the role of school food in wellbeing, social interactions, culture, or history. Food is a fundamental requirement of life, and while our knowledge of the nutritional values of foods and food groups, the psychological effects of foods, and the health benefits (or lack thereof) of foods continues to grow and expand, our sociological knowledge of the important role school food plays throughout our lives has had less attention (Murcott, 2019; Fossgard, 2018). Food security, both in the developed and developing world, is a focus of international policy, and a global concern. Feeding children has become a central part of food security talk (Murcott, 2011). Hunger and food poverty amongst children in the UK is at unprecedented levels, with many 
children eating only at school through the free school meals benefit ${ }^{1}$. Poulain (2017) who also talks extensively about paying more attention to the Sociology of Food as a discipline, outlines how the meal rests at the heart of the socialisation process and does so in two ways. Firstly, an eating space is said to be a site of apprenticeship where life skills of a given community are learned, and second, it is a place for sociality, sharing and conviviality. Food served in schools forms part of this process of socialisation (Lalli, 2019a) and understanding the way school food is framed within policy, and how this affects micro daily experiences of eating, is important for our understanding of the role of school meals within English society (and more broadly).

School food in England has been the focus of significant policy change since the turn of the millennium (Hart, 2016; Morgan, 2006). Much has been made by the English government about providing children with healthy lunches, and justification for this provision is usually organized along two lines: 1) healthy lunches provide young people with a balanced meal in the middle of the day. This meal teaches them how to eat healthy foods, and will benefit both their current and (more crucially) their future health. This will go some way to curbing the obesity crisis; 2) healthy lunches allow young people to concentrate better in class. They do not suffer from changing energy levels caused by eating sugars (including refined carbohydrates) and provide a meal for children for whom no other food may be available during the day. Being able to concentrate in class allows students to do better in exams, ultimately enhancing their academic performance. It is implied that this will inevitably lead to improved scores in global rankings like PISA.

Positioning health and academic performance as key to the justification of school food policy

\footnotetext{
${ }^{1}$ Free school meals are provided to children from families who qualify for state benefits such as the Child Tax Credit or Income Support. All children in Reception, Years 1 and 2 are eligible for free school meals if they attend a government-funded school in England.
} 
indicates a societal focus not only on individual young people's health and wellbeing in the present, but on their future health and performance. We think this future-oriented focus highlights a number of questions. What is the purpose of school? Is it merely a place to seek results in league tables and rankings, based on exams and test scores? Or is it a place where we mould children into citizens? What role might school meals play beyond a simple nourishing meal or eating experience? How do spaces like the dining hall function as educational spaces and what learning takes place that is unrelated to academic subjects, but still potentially valuable? What does this focus on future selves reveal about the current education system? In this paper we explore these concerns.

Policy approaches to the provision of school meals

Links between academic performance and school meals is one of the policy justifications within the School Food Plan (2013), the most recent English policy document regarding school meals. The other focus of the School Food Plan (2013) is health. The main motivation for providing school meals is to improve the health of children, particularly in response to rising childhood obesity rates worldwide. Medical and nutrition literature has supported the view that a healthy diet can have an impact on an improvement in cognitive function (Anderson et al. 2018). The relationship between cognitive function, test scores and meals is reliant upon the nutritional quality of the meal consumed (Anderson et al. 2018, 30).

The UK has seen a significant improvement to school meals offered since 2001 when nutritional standards were introduced. Following on from Scotland's Hungry for Success (2002) report, further changes (35 recommendations) were made in the English Turning the Tables report (2005). Simultaneously, Jamie's School Dinners (2004) thrust school meals into the limelight, drawing public attention to the way children were being fed in schools. School meals were widely ridiculed within the media and seen as 'failing children and failing 
society' (Metcalfe, 2010: 377). The School Meals Review Panel report, Turning the Tables, introduced new nutrition standards, and took a sustainable, local approach towards procurement, as well as calling for "more resources, new skills and higher food standards" (Morgan, 2006, p.382).

More recently, the School Food Plan (Department for Education, 2013) introduced a new set of recommendations. These included simplifying the nutrition and food standards, providing better training for school cooks, and teaching young people to cook. Crucially though, The School Food Plan also thinks about food beyond the school meal. Ideas include: good food, happiness, growing, cooking and eating 'proper' food as well as improving overall health and the academic performance of today's youth (DfE, 2013, p.7). Here we see the two strands of school food policy justification: future health and academic performance.

Elliott and Hoare (2016) identified a number of discourses within The School Food Plan. They noted that school attainment was the first and notably, the least controversial of the discourses they identified. They argue that attainment is not seen by the government as the most important consequence of food availability in schools, although it appears as one of the ways to justify the need for the policy and a school meals review. Elliott and Hoare (2016) identify a number of other discourses that shape the policy, including health, community, values, and the moral dimensions of food in schools.

In terms of the policy discourse, there is much debate surrounding the priority in shaping and enforcing nutritional values of school meals (School Food Plan, 2013) but very little on the health and wellbeing of the 'whole child'. Policymakers have focused on making children 'healthy' with little attention to how we might think of this beyond simple physical health. 
Policymakers are guided by what Gaztambide-Fernandez (2013, p.211) has termed "the rhetoric of effect", a focus on results. Gaztambide-Fernandez has argued in relation to arts education that "framing the arts through their consequences gloss over the actual experience and practice of arts education" (2013, p.216). In short, framing experiences in terms of their consequences or outcomes misses valuable experiences that contribute to human wellbeing. We think this analysis can similarly be applied to understanding school meals as more than ways to health or academic success. We think there is a role for food in education that is beyond the contribution to physical good health or academic success.

Rethinking the framing of school food policy

We find it useful to conceive of food provision in schools as part of a wider approach towards societal capabilities. The Capability Approach, as formed by Nussbaum (2011), provides a way to think about food in schools as being more than simply about contributing to health or to academic attainment and performance. The capability approach asks the question 'what are people actually able to do and to be? What real opportunities are available to them?' (Nussbaum, 2011, p.43). As one of us has written elsewhere, food is often simplified to a healthy/not healthy binary - this is how information about food is imparted in schools through classes on 'healthy eating', posters on 'healthy and unhealthy foods' and restrictions on food choices at lunchtime. The complexity of food practices and the place of food in wider life are lost through these simplified binary definitions (Earl, 2018c). The capability approach allows for complicated and complex food practices, in schools and elsewhere. The capability approach is focused on freedom, arguing that 'the crucial good societies should be promoting for their people is a set of opportunities, or substantial freedoms, which people then may or may not exercise in action' (p.18). The key aspect of the capability approach is that people 
are able to live a life of human dignity of their choice. Nussbaum argues that the role of government is to actively support people's capabilities, not just fail to set up obstacles (p.65). In particular, Nussbaum argues that governments should not make people lead healthy lives. Rather, governments should provide people with the capabilities to lead healthy lives if they so choose. Nussbaum argues that there is a moral difference "between a policy that promotes health and one that promotes health capabilities" $(2011$, p.26). It is the one that promotes health capabilities that is most supportive of people's freedoms.

We think this is at the crux of understanding the justification for food in schools. Rather than narrowing down particular active results or outcomes that providing food will result in, the capability approach allows us to conceive of food in schools, as an end in itself. The focus of the approach is of each person as an end (p.18), and it is useful when thinking of food, young people, choice, health, attainment, to think about each young person as an end in themselves, in their own right. The everyday experience of food in schools is much more complicated than the policy suggests. There is much more going on around food in schools than simply eating to be physically healthy, or eating to improve academic success, although both these elements exist.

\section{Educational Ethnographies of Eating}

This paper draws on data from two ethnographic research projects carried out in the East Midlands in England. This section provides an overview of the two research studies referred to in the paper (Earl, 2015a and Lalli, 2017). An ethnographic case study was carried out in one school, known as Peartree Academy (Lalli, 2017). This school was unique in that the school dining hall was rebuilt as a 'restaurant' and the study explored this space to understand how social learning opportunities shaped children's experiences in a school which 
was geographically located in a deprived inner-city area. Social learning is defined as a new way of viewing school mealtimes in which children area able to learn positive eating behaviours (Dalton, 2004). In total, 54 interviews were carried out alongside 80 hours of structured observations between October 2013 and June 2014, using an opportunity sample. 26 of the 54 interviews were carried out with a wide range of staff. These included the leadership team, teachers, support tutors, midday supervisors and the administration team. Interviews were also conducted with 12 parents and 16 pupils ( 8 male and 8 female pupils). The main research question was titled, what is the impact of the food environment upon social learning? This was followed by two subsidiary questions: 1) How do eating behaviours of staff and pupils impact on social learning? 2) How do teaching staff promote social learning opportunities within a food environment? There were no conscious decisions made to interview the parents or teachers who had contact with the particular pupils involved in the study.

Earl (2015, 2018a) conducted a multi-sited ethnography (Keller 2004) in three different primary schools. The schools were recruited in different stages, and the recruitment process is written about elsewhere (see: Earl 2015). The focus of the research was on food experiences across the school day, from breakfast club into the classroom, the dining hall, the kitchens, and in other spaces like gardens and farms. The research explored how policy is enacted in schools, how schools speak back to policy, and the way policy formation is a back and forth dynamic process - practices already existing in schools are taken up and encoded into policy texts (Ball et al., 2012). The research took place in 2012/2013 and was therefore 'bookended' by two different policies: Turning the Tables (2005) and The School Food Plan (2013). This process of back and forth exchange was therefore witnessed and explored in depth. 
Each school in Earl (2018b) research was situated in a different environment (urban, suburban, and rural) and presented a different socio-economic catchment area. Interviews were conducted with head teachers, head cooks, head dining hall supervisors, and Year 5 class teachers in each school. Additional teachers and school staff involved in food education programmes (cookery teachers, farm staff, gardening programme teachers) were interviewed. These people differed according to site, as the schools offered various food education opportunities and therefore the people to talk to varied. Year 5 children were engaged in a foodscapes mapping activity in order to explore children's views of school food experiences (see: Earl 2018b).

The rest of this paper illustrates the complexity of food practices and experiences in schools, using examples from the two ethnographic research projects elaborated above. Throughout, we will draw on Nussbaum's ideas of capabilities, and the way food in schools does more than simply improve health or academic results.

Social learning in the dining hall It is said that learning in schools traditionally takes place through formal instruction in a given space in which the teacher facilitates activity. Social and environmental influences can have an impact on children's eating in school and teachers, alongside dining hall attendants are said to be the 'significant others' in encouraging children to make good food choices (Roberts and Marvin, 2011). Whilst eating habits are modelled in terms of consumption, school dining halls are also spaces of discipline and control within a moral discourse (Metcalfe et al. 2010, Pike and Kelly, 2014). We do not dispute this. Dining halls can be stressful spaces, with the organisation of bodies, queues, and noise overwhelming at times. 
However, the school dining hall can become another place for a form of instruction, a continuation of learning, though that of a different type - social learning (Lalli, 2019a; 2019b). To understand social learning, we would like to define social as being part of an organised community, and learning as including skills which have to be practiced as well as knowing how to behave in a social context (Dalton, 2004). We know that often social learning is lost in the hustle and bustle of lunchtimes, the 'pupil processing system' Metcalfe et al. (2010) identified. However, the overall potentials of the dining space were identified by members of staff at Peartree Academy:

'...but it's also being together and being sociable and eating together, they are learning other things, they are learning social skills and I think that's one of the main drives to creating the restaurant to allow them to be socialised. Some of the pupils have difficulty with socialisation' (English Teacher, Peartree, 2014).

Similarly, at Jevington School, the head teacher explained:

So the whole sense of sitting became part of that more social educational aspect of it, learn to sit with each other and guess what the only queue you've got to go into then is when it's your table's turn to go up and I could now almost take all the adults out the hall and the children's organise themselves. You know on a good day you don't really need the adults there very much cause that's the selfdiscipline that they've learnt (HT, Jevington, 2012).

Mealtimes, as described by the English and Head teachers above, are considered as a cultural site for the socialisation of individuals into 'competent and appropriate members of a society' (Ochs and Shohet, 2006: 35). The interaction between pupil and teachers, or pupils and their friends during mealtime can be a vehicle for supporting the well-being of young people and ensuring pupils are able to communicate together at a time of day which is often loud, noisy and neglected as a space (Pike and Kelly 2014). At Jevington School, this was done by organising the process of receiving food into a table-by-table order, rather than as an entire queue. In this way, pupils were encouraged to sit and talk together while they waited to be 
called to get their food, the queue process was shorter, and they could then return with their food to eat their meal and continue conversations with friends.

It is just as important to harness social learning whilst setting appropriate rules to minimise behavioural disruption. Often, social learning is not instructional - children do not necessarily receive verbal or physical guidance on how to do these social things. Rather they are inferred.

'...they're learning social skills, also manners, and eating skills cutting up food and just general table manners, I'm in charge of a team of midday supervisors, and I always encourage them to show how to set a good example to the children. I always encourage them to help them with the food but to encourage the children to do it for themselves, help them learn' (Pupil Guidance Leader, Peartree, 2014)

'...just talking to their peers as well as the adults in a polite manner, not just shouting across, talking in small groups, being polite to adults and listening, doing as there asked, walking sensibly' (Pupil Guidance Leader, Peartree, 2014)

Well its learning social skills, it's what they should or shouldn't be doing over a lunchtime period, how to line up, how to get to the till, how to behave responsibly, how to act with your peers' (Assistant Phase Leader, Peartree, 2014)

Technically if you think specially with the young children, you need an adult per table to encourage correct knife and fork use, good table manners, to be encouraged to try different types of food (TA, Framley Primary, 2012).

The examples above (from Peartree Academy and Framley Primary) invoke the complexity in understanding of the term 'social skills'. Social skills can include table manners, politeness, conversations that are not too loud, using a knife and fork, or trying different types of foods. The emphasis on behavioural activity is highlighted by the Pupil Guidance Leader at Peartree Academy. They describe how they encourages their team of midday lunch supervisors to portray good examples to pupils, including being polite and respecting adults in the dining hall through paying close attention to set instructions. Whilst there is very little research on the impact of food on social learning (Lalli, 2019a; 2019b) in the context of school meals, the examples above illustrate how people identify the dining space as 
something more than a space for eating. Eating follows various cultural rules, and children learn these (indirectly) through their participation in the meal.

Children also learn through direct modelling of social skills. Children's eating behaviours are closely linked to families and it is through positive role modelling that children are able to try new foods and develop an attitude similar to those of adults (Eliassen, 2011; DeCosta, 2017; Scaglioni et al., 2018). To learn by example appears as a common theme in the work on school meal research (Lalli, 2019a; 2019b) and it is modelling of appropriate behaviours by both teachers-pupils and pupils-pupils. For example:

'By example I think as well, by instruction and example, it's quite different here because we've got the years right from little so they sort of learn it you know the routine of the restaurant from a tiny little dot, you must have seen them yeah, lining up and waiting to go and then we've got them sitting down, we sit down, they sit down, and they're quite closer to the older year, cos we have a staggered lunch time say for example we have a 5, 6 and 8 lunch, with younger pupils as well, younger pupils will see that the older kids, and there's a 7 and 9 lunch and I think there's youngers pupils with the 7 and 9 lunch, so they can see sort as well, the year $9 \mathrm{~s}$, how they behave, and even in the change in the uniforms, the much older years, I think the 10 and 11 are independent, I don't think they have younger kids in there, its learn by example, a lot of learn by example' (Assistant Phase Leader, Peartree, 2014).

A large part of instruction consists of conforming to a set of rules and it is these rules that govern the confines of the school dining hall as a space which needs careful control in order to create 'good citizens' (Pike and Leahy, 2012). The link between younger pupils interacting with older pupils also supports a form of social learning through modelling. The example below signifies how pupils can become familiar with the rules and etiquette around mealtime and how to behave appropriately whilst interacting with adults.

'... and it's trying to get them and gain establish patterns of behaviour, establishing norms for how you should behave in certain situations and so apart from the formal academic side of learning, there are also other patterns of learning going on that feed into their normal learning because we find that some pupils, if they're below a certain level of socialisation, they can't access the learning anyway, because they don't know how to behave in the classroom, they 
don't know how to speak to adults, they don't know how to interact with children their own age, so it's all part of the same' (English Teacher, Peartree, 2014)

[We have] very supportive staff who encourage children. I have seen evidence because I'm in there [dining hall] most of the times, of staff helping them to use a knife and a fork, teaching them. That's important; again we're back to life skills (HT, Framley Primary, 2012).

Social learning contributes to young people's abilities to navigate the world outside of school. Yet, as we have seen in this section, this type of learning is not formalized, nor is it recognized as part of teaching. The dining hall is seen as a space where eating takes place but not as a place where learning takes place. Social learning needs to be considered as having equal importance in fostering opportunities for a type of learning which prepares pupils for life after school (Murray, 2017), such as helping to 'fit' into community by creating cohesion.

This social learning, and the social skills that accompany this learning, then enable children to go out into the world and participate in social situations. They are being given the capabilities for managing in a world where food consumption has become public (through Instagram, food blogs, and food media (REF)). These social skills are developing 'internal capabilities' (Nussbaum, 2011, p.21) - those abilities that can be trained and developed through education (or through social interactions). The school dining hall provides a site where young people are exposed to, educated about, and develop skills of social interaction. These social skills can then be used by young people as and when they need them, allowing them to participate in society more widely. When used with 'combined capabilities' (Nussbaum, 2011, p.21), which we will draw on below, young people are able to use their internal capability within the social environment as they choose. 
Food identities and food choices

Food forms part of wider cultural, class, ethnic and religious traditions and experiences. It can be a key marker of identity. For instance, food rules are said to express an ideology of life that focuses on how and what is eaten and as a result class, race, ethnic and even gender boundaries are maintained by eating differences (Counihan, 2018, Douglas 1997).

Children bring these food identities and traditions with them into the dining hall, shaping their experiences and the experiences of their peers. This becomes even more pronounced when children bring lunch from home. Food experiences are malleable - they change over time, as do food tastes.

For example, at Jevington School, some of the Year Five children explained how they switched their food choices depending on what was on offer at lunchtime.

Patty: Oh yeah. And if you're vegetarian you can have the vegetarian option. It's really nice

Flora: Is it?

Patty: I even sometimes have the vegetarian option and I'm not a vegetarian.

Hetty: Me too. I have them like loads.

Patty: Yeah (FG5, Jevington, 2012).

Flexibility over choice at lunchtimes offers pupils the opportunity to try on different food selves, experimenting with what foods they like, and how they might identify themselves. In the example above, Patty explains that she sometimes chooses the vegetarian option even though she is not strictly vegetarian, because 'it's really nice'. Children at Jevington School were able to make their choice when they got to the front of the queue, unlike the two other schools in the study, where choice either had to be made in the morning, or there was no choice at all. 
All of these choices ${ }^{2}$ were governed by food and nutrition standards and so all could be classified as 'healthy' to a certain degree. Children were given a main meal, followed by a dessert. At both Jevington and Framley, there were choices for dessert. Several days a week there was a cake/pastry/pudding, as well as fruit or yoghurt. Children were therefore able to choose which dessert they fancied, and not all children opted for the pudding option.

Children are whole beings, rather than becomings (Qvortrup, 2009), and are capable of forming their own food subjectivities. As one of us has written elsewhere (Earl, 2018a), approaches to food education that are broad, that emphasise a form of balance, and that do not promote food for health or academic performance, allow children to adopt different subjectivities, even temporarily. They can 'try on' food selves without there being a moral consequence (i.e. 'those are bad foods') to their choices. Being able to choose which type of dessert one wanted, without a stigma being attached to any option, provided children with this experience.

We believe that an approach which centres child wellbeing, that avoids dichotomies of good/bad foods, and which allows children to experiment with food subjectivities is useful Although, it is important that as citizens we develop positive eating behaviours and as participants of a community, provide children with food environments and experiences that have positive influence on their behaviours, allowing them to do so in a diverse and nonjudgmental way, distinct from ideas of health or achievement, is hugely important.

Schools must move away from value judgements around certain foods, and recognise that food spaces are far more complex than we imagine. Associating some foods with good health and academic performance turns other foods into 'bad foods'. This is helpful for no one, but particularly not young people, some of whom may not have a wide choice in the foods they consume. Moral judgments attached to foods detract from children's abilities to

\footnotetext{
${ }^{2}$ We are aware that the notion of 'choice' in school is still heavily restricted and managed through adult rules.
} 
develop critical skills regarding their food choice, and ultimately undermine their capabilities to live a life of their choosing.

The ability of young people to develop these critical capabilities then allows them to realise the functionings (Nussbaum, 2011, p.25) of these capabilities. For example, young people are able to critically assess the foods that they eat because they have been educated about the different food subjectivities they may encounter. This then may lead them to experience good health, which is a functioning. The purpose of these different food subjectivities and experiences is therefore beyond a particular agenda on health. Rather, it allows young people the freedom to choose their own food subjectivities, from an informed place.

Formal and informal learning spaces

The School Food Plan (DfE 2013) brought focus to the way children were being taught about food formally at school. This occurred predominately through cooking classes, but also occurs through learning about 'healthy eating' in Science and PSHE classes. The dining hall provides opportunities for both formal and informal learning, although how these occur is not well understood.

For example:

'They're learning about the story Goldilocks and Three Bears, so I make them porridge and then we talk about the story of goldilocks and how it works. You know the sort of things to introduce different things' (Catering Manager, Peartree, 2015).

Here, the catering manager is using the formal learning of Goldilocks and the Three Bears as an opportunity to link to food, eating, and tasting. Story-telling makes up some of the 
learning experiences for pupils, and food such as porridge (in this example) enables connections to be made between the story and the kinds of foods we eat. We don't know however, if children are able to declare their porridge as 'just right' or whether they find their porridge too hot or too cold. What the experience does do is reinforce an experience of storytelling through eating. Children learn through storytelling at school and they are exposed to the story of school dinners through mealtimes. If children are fulfilled during school mealtime, through positive experiences of social learning, friendship and wellbeing, then the story they will remember and tell would form the basis of them learning, growing and socialising; a form of social competence which is salient for life after school.

The preparation of food, distribution and consumption are said to authenticate both social order and moral beliefs and values (Ochs and Shohet, 2006). By using the dining hall as a more formal teaching area, norms, values and social order can be connected to the school experience. Schools can tie 'formal' lessons to eating, making the eating part of a more formal discourse on learning.

'The restaurant is used as a learning area as well, so I teach there, for a number of lessons every week and also see a lot of teachers doing similar things. The learning area, sometimes EAL, other times with English pupils doing work. I see a lot of teachers doing that and its formal academic teaching...' (English Teacher, Peartree, 2015).

The design of school buildings, and the effects this design has on children is relevant (Daniels et al., 2019), and the focus is on dining halls, which encompass social, physical and temporal characteristics and are known to influence eating experiences (Moore et al. 2010) enables an understanding of the way space affects experience. The example above shows the formal academic teaching taking place in the dining hall. Therefore, the importance of acknowledging this space is crucial in shaping the way we think about school meal provision 
and teachers need be trained and develop an awareness of ways to interact with pupils and recognise the effects of their behaviours (Osowski et al. 2013).

Another way in which the school dining hall is being used as a site of learning is through aesthetics, namely by delivering key messages to pupils. The school building is said to shape part of the way in which learning is taking place and this environmental adaption can become a tool for fulfilling ideas about how children learn (Nicholson, 2005). For example:

A wall display: 'Within the Academy we recognise that pupils who feel happy, safe and are valued and given opportunities to contribute to school life not only make more progress academically but also develop into more rounded and confident adults, ready to access a successful adult life' (Notes, Peartree, 2015).

The manipulation of aesthetics was also found in Earl's research. Dining halls displayed posters relating to eating (healthy $\mathrm{v}$ unhealthy foods with crotched examples), or relating to other food concepts that the school wanted to indicate they were participating in (like Fair Trade or Food for Life). As one of us has argued elsewhere (Earl, 2018b), the use of posters and information in dining halls serves as a signal to young people, parents, teachers, and other visitors, that the school is participating in particular discursive practices.

At one school in Earl's research, the head teacher explained the pressures on schools, and the ways that food learning needs to take place in the spaces in-between, where it can simply form part of a wider school culture.

"I've been a head 19 years now and, in that time, education has changed beyond imagining, even in my time as a head teacher, never mind before that. The only thing that hasn't changed is the length of the school day. So that the nature of what we have to teach, or should teach, has gone through the roof. As, you know, it's impossible to conceive how we fit everything in. From the massive onus on us to get kids through exams, to French, to $\mathrm{x}$ amount of sport or whatever that thing is, so food has to find its place and some of its place is that tweak where we just find an opportunity to talk about it; to make it real and meaningful. And other times it's a specific thing we're doing. Like making fruit salads for people in Year One, as part of Handa's Surprise, which also has a multi-cultural, respect for diversity element to it, and there in that cross-curricula sense where we're also drawing it, food can have its place. Just as food growing can have its place, but if 
we're going to grow it then Year Four need to grow potatoes or whatever Year Four grow, they can't grow everything because there's only a certain amount of time we can give to it, which is why dinners itself is so important, cause it's every day. The other thing is almost to serve children's understanding of where food comes from or what food is or its journey or how we can link to respect for other people in the world because they grow it for us and we love it, don't we? If you like chocolate, where do you think that comes from? We can do all of that through it but it can only be given its place because we only have a limited amount of time to tick all the boxes of which there are now many in a school day that doesn't change" (Head, Jevington School 2012)

In this quote we can see the tensions and challenges schools face when thinking about food beyond a vehicle for physical health or academic prowess. The principle problem is the lack of time in the school day, and the ever-changing pressures to educate children on a wider and wider curriculum with more and more assessments, with little acknowledgment from policymakers that cramming the curriculum with more things is almost impossible for schools to deliver. The idea that food might contribute to more than simply physical health is a hard sell, and yet something that is vitally important if we are going to change how we (as a society) think about food and eating as more than fuel.

Thinking beyond health and academic performance of school meals can allow us to catch a glimpse into food experiences that do not fit into either category, but show joy and happiness, in effect a functioning of a well-lived life not bound by government rules on what counts as 'good' food or health...

When she sees the dessert going to the table next to ours one of the girls says 'I love chocolate cakes!' I can't tell from my position what the dessert is yet so I nod. The dessert, when it arrives, is actually plain sponge and custard. The top of the sponge is slightly darker brown than the interior but it's definitely not chocolate. The handyman who helps out at lunch serves the group. Two don't want custard. 'I don't like custard' the girl says. 'My daddy is going to come to the school and be a dinner helper and when he does he'll tell everyone that I don't like custard.' She picks up a piece of the darker sponge in her spoon. 'I love chocolate' she says again, indicated the sponge. 'I love chocolate mousse too. Mmm' she continues. 'Chocolate mousse' she says again in an awed, reverential voice. The girl sitting next to her declares herself finished. She's eaten half the dessert. She leans back in her chair, her hands on her stomach and closes her eyes. There's a look of contentment and relaxation on her face (Notes, Fort Basset Academy, 2012). 
The notes above detail the end of a lunchtime, as children are eating and finishing their dessert. In provides a brief snapshot of contentment, as a child leans back after eating and closes their eyes. They have obviously gained pleasure from their eating experience, something oft forgotten in school meals policymaking. Providing children with the capabilities to experience pleasure, unbound for policies around health allows a freedom otherwise missed.

\section{Conclusion}

School, we have suggested through this paper, it is not merely a place for seeking results in national league tables based on education attainment. Nor is it a place where food can be devoted solely to pursuits of health. We have argued that school is a place for moulding children into citizens and that school meals go beyond a simple nourishing meal or eating experience. Schools are, and should be, more than sites for lunchbox surveillance (Fossgard et al. 2018) and the acquisition of educational qualifications. Schools need to be seen as places that prepare children and young people for life as social and cultural participants in society (Murray, 2017) and prepare them with the capabilities to live lives of their choosing. We have argued for the crucial good societies should and could be promoting through dining hall experiences, unencumbered by ideas of what counts as 'good' health. In terms of the school dining hall as an educational space, giving recognition to this space where children are able to continue learning, both through formal instruction, and through social learning and experience is important. School mealtimes need to be recognised beyond their nutritional and associated health benefits. The narrow focus on academic performance (and also on health) undermines the important role food plays in our society, our cultures, and our history. Ignoring these aspects is a "process of abstraction" (Gaztambide-Fernandez, 2013, p.222) and 
one that serves particular political agendas. Feeding children well, enabling them to live the lives of their choosing, should be the justification of school meals.

\section{Acknowledgements}

We would like to acknowledge both reviewers for their feedback throughout.

\section{Funding}

None to report

\section{ORCID}

Lexi Earl http://orcid.org/0000-0002-6906-3742

Gurpinder Singh Lalli https://orcid.org/0000-0002-7493-4813

\section{Declaration of interest statement}

The authors declare that they have no conflict of interest and that the research follows the University of Leicester and University of Nottingham's code of ethical practice and meets the requirements of the Human Subject Research (HSR) with children. All research conducted was carried out appropriately in conjunction with the HSR and British Educational Research (BERA, 2018) guidelines. 


\section{References}

Anderson, M. L., Gallagher, J. and Ramirez Ritchie, E. 2018. School meal quality and academic performance, USDA National Institute of Food and Agriculture Report. http://www.nber.org/papers/w23218.

Benn, J. and Carlsson, M. 2014. "Learning through school meals?” Appetite, 78: 2331.

Counihan, C. M. 2018. The Anthropology of Food and Body: Gender, Meaning and Power. London: Routledge.

Dalton, T. A. 2004. The food and Beveridge handbook. Cape Town: Juta Academic.

Daniels, H., Tse, H. M., Ferrand, L. O., Stables, A., Cox, S. 2019. “Changing schools: A study of primary secondary transfer using Vygotsky and Bernstein", British Journal of Sociology of Education, DOI: https://doi.org/10.1080/01425692.2019.1601546.

DeCosta, P., Moller, P., Frost, M. B., Olsen, A. 2017. “Changing children's eating behaviour - A review of experimental research", Appetite, 113 (1): 327-357.

Department for Education. 2013. The school food plan: How to improve school food and schoolchildren's diets. https://www.gov.uk/government/publications/the-school-foodplan. 
Dudley, D. A., Cotton, W. G. Peralta, L. R. 2015. "Teaching approaches and strategies that promote healthy eating in primary school children: A systematic review and meta-analysis", International Journal of Behavioural Nutrition and Physical Activity, 12 (28), DOI: 10.1186/s12966-015-0182-8.

Earl, Lexi. 2015. 'Are we all foodies now? An ethnographic exploration of food experience in primary schools'. PhD diss., University of Nottingham.

Earl, L. 2018a. Schools and Food Education in the 21st Century. Abingdon: Routledge.

Earl, L. 2018b. “Children's food maps: Using social mapping to understand school foodscapes". Ethnography and Education 13 (4): 508-528.

Earl, L. 2018c. Are we all foodies now? An ethnographic exploration of food experiences in primary schools. In: Kember, D. and Corbett, M. eds. Structuring the Thesis: Matching method, paradigm, theory and findings. London: Springer.

Eliassen, R. K. 2011. 'The impact of teachers and families on young children's eating behaviours'. http://www.naeyc.org/files/naeyc/Eliassen_0.pdf .

Fossgard, E., Wergedahl, H., Bjorkkjaer, T., Holthe, A. (2018) "School lunchChildren's space or teachers' governmentality?" International Journal of Consumer Studies. 43, pp. 218-226. 
Garthwaite, K. 2016. Hunger Pains: Life inside foodbank Britain. Bristol: Policy Press.

Gaztambide-Fernandez, R. 2013. "Why the arts don't do anything: Toward a new vision for cultural production in education". Harvard Educational Review. 83 (1): 211-237.

Hart, C. S. 2016. "The school food plan and the social context of food in schools". Cambridge Journal of Education. 46 (2): 211-231.

Haque, M. A., Farzana, F. D., Sultana, S., Raihan, M. J., Rahman, A. S., Waid, J. L., Choudhury, N., Ahmed, T. 2017. "Factors associated with child hunger among food insecure households in Bangladesh”. BMC Public Health. 17 (205), DOI: 10.1186/s12889-017-4108$\mathrm{Z}$.

Kwon, S., Kim, O., Lee, Y. 2018. "Effect of students' satisfaction with school meal programs on school happiness in South Korea”. Nutrition Research and Practice. 12 (4): $342-347$.

Lalli, G. 2017. 'The restaurant: A social learning space? PhD diss., University of Leicester.

Lalli, G. 2019a. Schools, Food and Social Learning. London: Routledge.

Lalli, G. 2019b. "School mealtime and social learning in England”. Cambridge Journal of Education. DOI: https://doi.org/10.1080/0305764X.2019.1630367. 
Metcalfe, A., Owen, J., Dryden, C., Shipton, G. 2010. "Concrete chips and soggy semolina: The contested spaces of the school dining hall". Population, Space and Place, 17: $377-389$.

Moore, S. N., Murphy, S., Tapper, K., Moore, L. 2010. “The social, physical and temporal characteristics of primary school dining halls and their implications for children's eating behaviours". Health Education, 110 (5): 399-411.

Murcott, A. 2019. Introducing the Sociology of Food and Eating. London: Bloomsbury.

Murcott, A. 2011. The BSA and the emergence of a 'Sociology of Food': A personal view. Sociological Research Online, 16 (3), pp. 14-15.

Murray, J. 2017. "Young children are human beings". International Journal of Early Years Education. 25 (4). Pp. 339-342.

Nelson, M., Nicholas, J., Riley, K., Wood, L. 2012. 'Seventh annual survey of take up of school lunches in England, Children's Food Trust.

Nicholson, E. 2005. The school building as third teacher, Ch. 4 in Dudek, M. ed. (2006) Children's Spaces. London: Routledge, pp. 44-65.

Nussbaum, M. C. 2011. Crating capabilities: The human development approach, Harvard: Belknap Press. 
O’Connell, R., Owen, C., Padley, M., Simon, A., Brannen, J. 2019. “Which types of family are at risk of food poverty in the UK? A relative deprivation approach”. Social Policy and Society, 18 (1) pp. 1-18.

Ochs, E. and Shohet, M. 2006. "The cultural structuring of mealtime socialisation". New Directions for Child and Adolescent Development, 111, pp. 35 - 49.

Osowski, C. P., Goranzon, H., Fjellstrom, C. 2013. “Teachers' interaction with children in the school meal situation: The example of pedagogic meals in Sweden", Journal of Nutrition Education and Behaviour, 45 (5): 420-427.

Poulain, J. P. 2017. The Sociology of Food: Eating and the place of food in society. London: Bloomsbury.

Pike, J. and Leahy, D. 2012. "School food and pedagogies of parenting”. Australian Journal of Adult Learning, 52 (3): 435-459.

Pike, J. and Kelly, P. 2014. The moral geographies of children, young people and food. New York: Palgrave Macmillan.

Qvortrup, J. (2009) “Are children human beings or human becomings? A critical assessment of outcome thinking”. Rivista Internazionale di Scienze Sociali, 3-4, pp.631-654.

Scaglioni, S., De Cosmi, V., Ciappolino, V., Parazzini, F., Brambilla, P., Agostoni, C. 2018. "Factors influencing children's eating behaviours". Nutrients. 10 (706), pp. 1-17. 
School Meals Review Panel. 2005. Turning the Tables: Transforming School Food. London: HMSO.

Scaglioni, S., De Cosmi, V., Ciappolino, V., Parazzini, F., Brambilla, P., Agostoni, C. 2018. "Factors influencing children's eating behaviours". Nutrients, 10 (6): 1 - 17.

Seaman, C. and Moss, J. 2006. "Generating effective change in school meals: a case study". Nutrition and Food Science, 36 (5): 305-314. 